\title{
Importância e versatilidade da madeira de eucalipto para a indústria de base florestal
}

Dalton Longue Júnior ${ }^{1}$, Jorge Luiz Colodette ${ }^{1}$

Universidade Federal de Viçosa, Laboratório de Celulose e Papel, Av. P H Rolfs, s/n, CEP 36570-000, Viçosa, MG, Brasil

"Autor correspondente:

daltonufv@yahoo.com.br

Termos para indexação:

Florestas plantadas

Produtos da madeira

Diversificação

Index terms:

Planted forest

Wood products

Diversification

Histórico do artigo:

Recebido em 15/05/2013

Aprovado em 25/11/2013

Publicado em 31/12/2013

doi: $10.4336 / 2013 . p f b .33 .76 .528$
Resumo - A diversificação do uso da madeira vem ganhando importância no cenário mundial por substituir produtos oriundos de fontes de recursos não renováveis, principalmente derivados do petróleo, como combustíveis e plásticos. Materiais oriundos de fontes renováveis como as florestas plantadas são importantes por minimizar a pressão sobre as florestas nativas e contribuir para a manutenção da qualidade de vida do planeta. As florestas plantadas de eucalipto abastecem considerável fração do mercado nacional de produtos florestais, incluindo produtos sólidos da madeira, carvão vegetal e papel e celulose. A busca pela utilização mais eficiente dos componentes da madeira de eucalipto tem despertado atenção, especialmente em relação a biocombustíveis e bioprodutos. $\mathrm{O}$ isolamento e a conversão da lignina e hemiceluloses da madeira em produtos de alto valor agregado como produtos químicos e biomateriais têm sido largamente estudados em associação com madeiras de eucalipto. O principal objetivo desse trabalho foi mostrar a importância e a versatilidade do uso da madeira de eucalipto como matéria prima para indústria de base florestal.

\section{Importance and versatility of eucalypt wood to forest-based industries}

\begin{abstract}
Diversified wood uses are getting more importance in the world, due to the use of wood as substitute of non-renewable resource products as fuels and plastics, derived mostly from petroleum. Materials from renewable natural resources as planted forests are relevant to minimize the pressure on native forests and contribute to maintain the life quality in the planet. The eucalypt plantation supply a significant amount of the national forest products market, including wood solid products, as lumber, charcoal, and pulp and paper. The search for a more efficient use of eucalypt wood compounds has getting attention, focusing on biofuel and by-products. The isolation and conversion of wood lignin and hemicellulose in products of high added value as chemicals and bio-products have been largely studied in association with eucalypt wood. The objective of this study was to show the importance and versatility of the eucalypt wood use on forest-based industries.
\end{abstract}




\section{Introdução}

Nativo da Austrália, o gênero Eucalyptus foi descrito pela primeira vez pelo botânico francês Charles Louis L'Héritier de Brutelle, em 1788. Pertencente à família Myrtaceae, conta com mais de 700 espécies já catalogadas, além de muitas variedades e alguns híbridos (Boscardin, 2009). O primeiro cientista brasileiro a estudar e cultivar o eucalipto foi Edmundo Navarro de Andrade, em 1904 que ao trabalhar para o setor ferroviário objetivava utilizar as árvores plantadas para abastecer as caldeiras das locomotivas, bem como para a produção de moirões e postes. Navarro de Andrade introduziu quase todas as espécies de eucalipto existentes no Horto de Rio Claro, São Paulo, constituindo desta forma um dos mais completos bancos de germoplasma do país (Ferreira \& Santos, 1997).

Apesar de um começo tímido e com poucas e simples aplicações, algumas espécies do gênero Eucalyptus passaram a apresentar grande potencial produtivo devido ao incentivo à pesquisa e à necessidade de abastecimento e desenvolvimento de alguns setores de base florestal brasileiros durante as décadas de 1970 e 1980 (Valverde et al., 2012). Como mostrado na Tabela 1, a madeira de espécies comerciais de Eucalyptus é principalmente utilizada pelos setores de celulose e papel, energia (lenha industrial e carvão vegetal) e para produção de produtos sólidos de madeira (madeira maciça e madeira industrializada). Empresas atuantes nos setores de celulose e papel e produtos sólidos de madeira utilizam o eucalipto para o suprimento direto de matéria-prima, enquanto empresas de outras áreas, como energia, o plantam principalmente para obtenção indireta de sua matéria-prima, o carvão vegetal.

Dentre as espécies florestais cultivadas no Brasil, o eucalipto se destaca perante o pinus e a teca, enquanto a região Sudeste se destaca como a principal produtora dessa essência, devido à maior concentração de empresas dos setores de celulose e papel e energia, com 59,3\% (Figura 1).

A madeira proveniente dos povoamentos de eucalipto era, até alguns anos, exclusivamente voltada para produção de matéria-prima ou abastecimento para as empresas dos grandes setores industriais brasileiros como celulose e papel, energia (siderurgia a carvão vegetal), moirões e postes. Porém, com o crescente

Tabela 1. Consumo brasileiro de madeira em tora para uso industrial por segmento.

\begin{tabular}{lcccc}
\hline \multirow{2}{*}{ Segmento } & \multicolumn{2}{c}{ Eucalipto } & \multicolumn{2}{c}{ Total por segmento } \\
\cline { 2 - 5 } & $\mathbf{m}^{\mathbf{3}}$ & $\mathbf{\%}$ & $\mathbf{m}^{\mathbf{3}}$ & $\mathbf{\%}^{(4)}$ \\
\hline Celulose e papel $^{*}$ & 53.239 .020 & 86,8 & 61.346 .966 & 36,1 \\
Energia $^{(1)}$ & 52.696 .088 & 85,5 & 61.661 .877 & 36,2 \\
Produtos de madeira $^{(2)}$ & 10.918 .851 & 23,7 & 46.088 .098 & 27,1 \\
Outros $^{(3)}$ & 774.144 & 73,0 & 1.059 .845 & 0,6 \\
\hline Total & 117.628 .103 & 69,1 & 170.156 .786 & 100 \\
\hline
\end{tabular}

${ }^{(1)}$ Inclui carvão vegetal e lenha industrial. ${ }^{(2)}$ Inclui os produtos sólidos de madeira como painéis industrializados e madeira tratada. ${ }^{(3)}$ Outros produtos de madeira como péletes e briquetes. ${ }^{(4)}$ Participação do segmento no consumo de madeira de florestas plantadas (Fonte: Valverde et al., 2012).
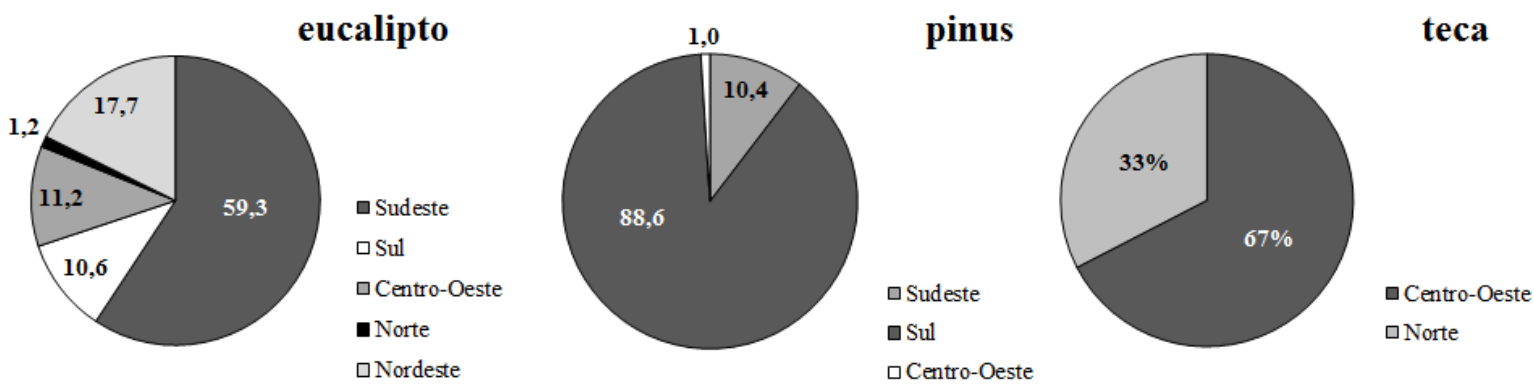

Figura 1. Área de florestas plantadas por região com as principais espécies cultivadas no Brasil (Fonte: Anuário..., 2012a). 
desenvolvimento de novos produtos e o aumento da demanda de mercado por produtos madeiráveis, as empresas do setor florestal buscaram ampliar as possibilidades de utilização da madeira e diversificar sua produção com bioprodutos derivados dos componentes da madeira, como, por exemplo, combustíveis e géis (Assis, 2000; Soares et al., 2003).

Em 2011, o segmento de celulose e papel concentrou $71,2 \%$ da área plantada de eucalipto, seguido pelos segmentos de siderurgia a carvão vegetal $(18,4 \%)$, painéis de madeira industrializada $(6,8 \%)$ e produtores independentes com 3,6\% (Anuário..., 2012a). Todos esses grandes setores, em especial o de celulose e papel, contribuíram para que o Brasil se tornasse um grande produtor dessa essência florestal, mostrando ao mundo a possibilidade de produzir papel de excelente qualidade de madeira de fibra curta e lançando o eucalipto como uma adequada matéria-prima, contrariando aqueles que acreditavam na produção de papel apenas das fibras longas das coníferas (Martin, 2012).

Dentre os fatores que conferem destaque aos eucaliptos brasileiros entre as matérias-primas, pode-se citar a alta produtividade das florestas atribuída ao clima tropical ou subtropical na maioria do território, o que permite um crescimento ininterrupto e, consequentemente, um rápido acúmulo de biomassa. Destacam-se também as condições de solo favoráveis, além dos diversos programas de melhoramento genético existentes, que contribuem significativamente para o fornecimento de material superior para os plantios, respeitando e adaptando as espécies às diferenças edafoclimáticas existentes nas diferentes regiões onde ele é cultivado no país (Associação Brasileira de Celulose e Papel, 2012; Valverde et al., 2012).

Como reflexo dessa alta produtividade, a idade de rotação dos plantios de eucalipto no Brasil varia entre cinco e sete anos, com produtividade de aproximadamente $44 \mathrm{~m}^{3} \mathrm{ha}^{-1} \mathrm{ano}^{-1}$, ao passo que em países de clima temperado como Portugal e Espanha varia entre doze e quinze anos com produtividade média de $11 \mathrm{~m}^{3} \mathrm{ha}^{-1} \mathrm{ano}^{-1}$ (Associação Brasileira de Celulose e Papel, 2012).

O Brasil possui atualmente cerca de 6,9 milhões de hectares em área com florestas plantadas, sendo $69,6 \%$ ocupada com eucalipto e $23,4 \%$ com pinus. Ainda existem plantios de teca (1\%) e de outras espécies de menor expressão $(6 \%)$ como acácia, araucária, pópulus, seringueira, paricá, entre outras (Anuário..., 2012a).
Dentre as espécies de eucalipto mais cultivadas podemse destacar o Eucalyptus grandis, Eucalyptus saligna, Eucalyptus camaldulensis, Eucalyptus urophylla, Eucalyptus viminalis, Eucalyptus dunnii, Eucalyptus pellita, bem como diversos outros híbridos (Garcia \& Pimentel-Gomes, 1992). Estima-se que a área de plantio mundial em eucalipto seja hoje em torno de 20 milhões de hectares, estando mais de $20 \%$ destas áreas localizadas no Brasil (GIT Forestry Consulting, 2009).

Apesar da grande vocação florestal, o Brasil ainda não explora todo seu potencial produtivo, tanto para o cultivo quanto para a geração de produtos derivados de madeira. Apesar de ser considerado um país de dimensões continentais, o Brasil possui percentualmente menos áreas com florestas plantadas que outros pequenos países como a Finlândia e o Japão e apresenta uma área total com florestas plantadas muito menor que os Estados Unidos e a China, seus tradicionais competidores (Tabela 2).

Tabela 2. Comparativo entre áreas de florestas plantadas em diferentes países.

\begin{tabular}{lccc}
\hline \multicolumn{1}{c}{ Países } & $\begin{array}{c}\text { Área total do } \\
\text { país(1000 ha) }\end{array}$ & $\begin{array}{c}\text { Área com florestas } \\
\text { plantadas (1000 ha) }^{(\mathbf{1})}\end{array}$ & \% \\
\hline Japão & 36.450 & 10.326 & 28,3 \\
Finlândia & 30.409 & 5.904 & 19,4 \\
Alemanha & 34,887 & 5.283 & 15,1 \\
Suécia & 41.033 & 3.613 & 8,8 \\
China & 942.530 & 77.157 & 8,2 \\
Índia & 297,319 & 10.211 & 3,4 \\
Chile & 74.880 & 2.384 & 3,2 \\
Estados Unidos & 916.193 & 25.363 & 2,8 \\
Indonésia & 181.157 & 3.549 & 2,0 \\
Brasil ${ }^{(2)}$ & 851.196 & 6.973 & 0,8 \\
Celulose e & & 2.196 & 0,3 \\
papel $^{(3)}$ & & & \\
\hline
\end{tabular}

Fonte: (1)FAO, (2011); (2)Anuário...,( 2012a; 2012b).

Nesse contexto de valorização da madeira de eucalipto, o objetivo desse estudo foi mostrar a importância e a versatilidade da sua utilização como matéria-prima para a indústria brasileira de base florestal.

\section{Eucalipto com fonte de produtos sólidos de madeira}

Entende-se por produtos sólidos a madeira maciça, a madeira utilizada na forma roliça, falquejada ou serrada e a madeira industrializada, que engloba todos os painéis produzidos a partir de lâminas/fragmentos de madeira 
(compensados, laminados, painéis reconstituídos de madeira e chapas de fibras).

A madeira maciça de eucalipto pode ser utilizada na forma de toras o que exige um menor grau de processamento, podendo ser empregada de forma temporária em escoramento de lajes e montagem de andaimes na construção civil, bem como de forma definitiva na construção de postes de distribuição de energia elétrica. As toras roliças ou falquejadas (trabalhadas apenas no machado), após serem tratadas com substâncias preservativas, são também comumente utilizadas na construção de residências, exercendo funções estruturais como vigas, colunas e treliças de telhados. Em alguns casos, as estruturas são exibidas devido à beleza apresentada pelas peças de madeira. Também é muito comum encontrar madeira maciça tratada em estruturas de pontes e cercas, principalmente em localidades rurais. Segundo alguns levantamentos (FAO, 2013), a produção mundial de madeira maciça para diversos usos foi estimada em 1.578 milhões de metros cúbicos em 2011, com aumento de 3,3\% em relação a 2010.

A produção anual mundial de madeira serrada foi de 400 milhões de metros cúbicos em 2011, um aumento de 4,2\% em relação a 2010 e 11,8\% em relação a 2009.

Estima $^{-}$se que a produção madeireira potencial de eucalipto, pinus e teca seja da ordem 255,4 milhões de $\mathrm{m}^{3}$ ano $^{-1}$, ao considerar a atual área de plantios florestais e o incremento médio anual (IMA) para cada região brasileira (Anuário..., 2012a).

As serrarias juntamente com a indústria de painéis à base de madeira destacam-se no segmento de produtos sólidos de madeira no Brasil, onde as diversas operações pelas quais as toras passam são determinadas pelos produtos que serão fabricados. As serrarias produzem maior diversidade de produtos, como pranchas, pranchões, blocos, tábuas, caibros, vigas, sarrafos, pontaletes e ripas, resultando em peças com dimensões variáveis e em diferentes graus de acabamento para uso externo e interno (Ferreira, 2003; Murara Junior et al., 2005).

O Brasil produz cerca de 120 milhões de metros cúbicos de madeira em toras (MTT - madeira em tora total), sendo $37 \%$ de coníferas (MTC - madeira em tora conífera) e 63\% de não-coníferas (MTNC madeira em tora não conífera), e nesta está agrupado o eucalipto (FAO, 2011). A produção brasileira de madeira em toras tem aumentado nos últimos anos por causa do desenvolvimento do país (Figura 2), podendo ser observado principalmente o aumento da produção de madeiras de não coníferas, pela diversificação e uso múltiplo conferido pelo eucalipto (Soares et al., 2003), com destaque para o setor de celulose e papel que utiliza principalmente as toras de menor diâmetro.

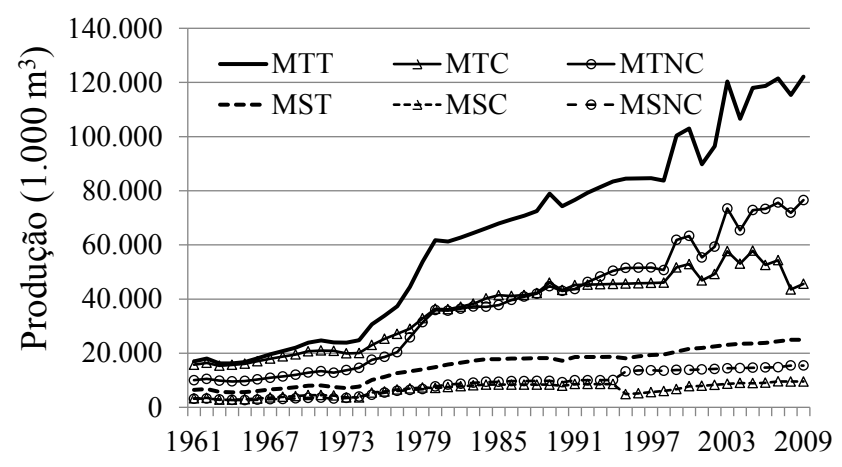

Figura 2. Evolução da produção brasileira de madeira em tora e serrada. $\mathrm{MTT}=$ madeira em tora total; $\mathrm{MTC}=$ madeira em tora conífera; MTNC = madeira em tora não conífera; MST = madeira serrada total MSC = madeira serrada conífera; $\mathrm{MSNC}=$ madeira serrada não conífera.

A produção de madeira serrada brasileira é de mais de 20 milhões de metros cúbicos (MST - madeira serrada total), dos quais $46 \%$ são de coníferas (MSC - madeira serrada conífera) e $54 \%$ de não coníferas (MSNC madeira serrada não conífera). A madeira de não conífera origina-se quase que totalmente da Floresta Amazônica, ao passo que as coníferas são produzidas principalmente na região Sul nas florestas plantadas de pinus (FAO, 2011).

Na Figura 2 também pode ser verificado que as serrarias são responsáveis pela produção de quase 25 milhões de metros cúbicos de madeira, utilizando um total de $20 \%$ da produção brasileira de madeira em tora (FAO, 2011). Nesse ramo da indústria não é tão notório o crescimento da utilização da madeira de eucalipto, devido ao uso em maior escala das madeiras nativas. Entretanto, existe uma série de produtos classificados como painéis de madeira que concorrem com a madeira serrada nativa e utilizam, na maioria das vezes, as madeiras de eucalipto para sua produção.

A indústria nacional de madeira serrada apresenta investimentos relativamente baixos em tecnologia e mão de obra com pouca qualificação. Isso leva a um baixo rendimento/eficiência de conversão das toras de madeira em madeira serrada. Entretanto, o setor abastece 
adequadamente a indústria moveleira nacional e ainda apresenta um grande potencial exportador.

Ainda sobre a produção de madeira em toras no Brasil pode-se dizer que existem aproximadamente 300 unidades industriais de preservação de madeira, distribuídas predominantemente nas regiões Sudeste e Sul, onde se concentram as maiores áreas reflorestadas. Tais indústrias possuem uma capacidade instalada para produção de 2,0 milhões de metros cúbicos, embora a produção do setor corresponda a 1,5 milhões de metros cúbicos. $\mathrm{O}$ mercado brasileiro consumidor de madeira tratada pode ser dividido em segmento rural, elétrico, ferroviário e construção civil. O consumo desses segmentos representa um faturamento de R $\$ 750$ milhões por ano, em que os principais produtos são mourões, cruzetas e postes, sendo a madeira de eucalipto muito utilizada (Anuário..., 2012a).

Apesar de sua grande utilidade, a madeira vem sendo substituída por outros materiais como aço, alumínio e suas ligas, e plásticos. Mesmo assim, ela continua sendo um material intensa e extensivamente usado, principalmente pelos países mais desenvolvidos tecnológica e economicamente, seja por suas características tecnológicas ou ornamentais (Gesualdo, 2003; Maia et al., 2011; Madeirambiente, 2013). Vale a pena lembrar ainda a grande importância da madeira na reciclagem de carbono da atmosfera, o que torna esse material também de extrema importância ecológica.

\section{Madeira de eucalipto como fonte de energia}

Sob o ponto de vista energético, a madeira pode ser chamada de lenha e sempre foi uma fonte de energia barata e de fácil acesso, sendo utilizada desde o início da humanidade para aquecimento e cocção de alimentos (Lima, 1993). Ao longo dos tempos, a madeira também passou a ser utilizada como combustível, em processos para a geração de energia térmica, mecânica e elétrica (Brito, 2007).

A crescente demanda mundial por combustíveis e o elevado consumo de combustíveis fósseis têm despertado uma preocupação global por se tratar de uma fonte de energia não renovável e altamente agressiva ao meio ambiente. Os aumentos constantes do preço do petróleo, a incerteza política dos principais países exportadores e o acréscimo de emissões dos gases causadores do efeito estufa tem colocado a biomassa, incluindo a madeira, no foco das atenções como uma importante fonte de energia (Brito, 2007). Nesse contexto, a madeira de eucalipto surge como uma fonte altamente atrativa sob o ponto de vista social, ecológico e econômico, pois pode ser cultivada em várias regiões do mundo e é uma fonte renovável de matéria-prima.

A madeira utilizada na sua forma direta como lenha ou como seu derivado, o carvão vegetal, é considerada um combustível essencial para o preparo de alimentos, principalmente em países em desenvolvimento, ao sustentar processos de secagem, cozimento, fermentação e produção de eletricidade (FAO, 2003). Apesar de ser menos consumida pelos países desenvolvidos como fonte de energia, a madeira também possui um papel importante porque é uma fonte renovável, o que a potencializa como alternativa aos combustíveis fósseis, conduzindo o seu uso à diminuição das emissões de gases do efeito estufa (Brito, 1994).

Portanto, o uso da madeira como fonte energética se correlaciona forte e negativamente com o grau de desenvolvimento dos países, como pode ser verificado na Figura 3 (World Resources Institute, 2013).

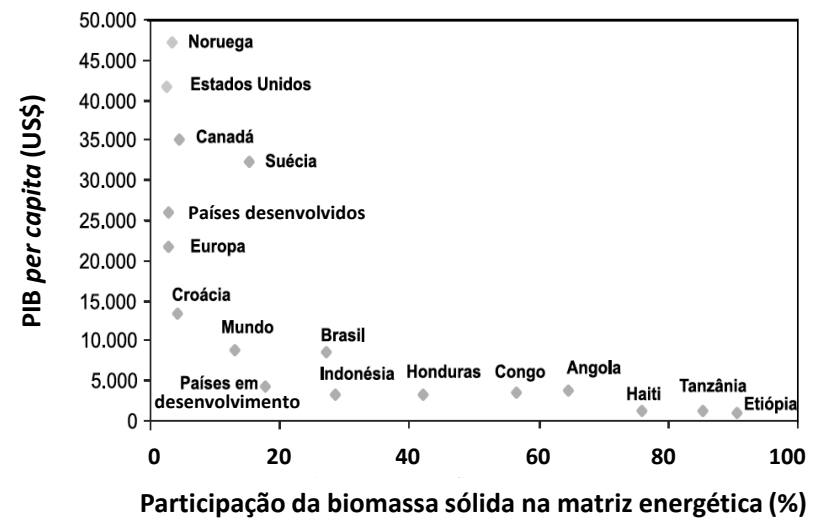

Figura 3. Porcentagem de biomassa sólida na matriz energética e PIB (Fonte: World Resources Institute, 2013).

Embora o consumo de lenha para geração de energia doméstica seja tradicionalmente um indicador do nível de subdesenvolvimento econômico de uma região, no caso brasileiro este aumento é decorrente do crescimento industrial (siderurgia a carvão vegetal, agroindústria, indústria cerâmica e de alimentos), tendo sido criado o termo "florestas energéticas" para o cultivo do eucalipto e pinus destinados a fornecer madeira para a geração de energia, principalmente para processos industriais. As florestas plantadas para fins energéticos apresentam um cenário bastante promissor, e por ser uma fonte renovável, a lenha originária das florestas energéticas possui a capacidade de contribuir para o crescimento sustentável dos setores industriais consumidores de biomassa florestal (Anuário..., 2012a). 
Dentre os produtos sólidos de madeira utilizados como fonte de energia, pode-se citar os briquetes, os cavacos de madeira, os toretes quarteados, os péletes e o carvão vegetal (Portal das Energias Renováveis, 2011). Recentemente, os péletes e os briquetes têm ganhado mais atenção, pois permitem o reaproveitamento de resíduos de madeira em sua composição. Entretanto, o carvão vegetal é um dos produtos energéticos mais produzidos e utilizados pelas indústrias produtoras de aço no Brasil, particularmente em Minas Gerais (Rezende \& Santos, 2012).

O Brasil é um grande produtor e consumidor de carvão vegetal, com uma produção de 6,8 milhões de toneladas, sendo a madeira proveniente de florestas nativas e plantadas, com um grande potencial para a substituição da madeira nativa por madeira de eucalipto (Figura 4). Este insumo energético é em grande parte utilizado pelo setor siderúrgico brasileiro (Associação Brasileira de Florestas Renováveis, 1995; Rezende \& Santos, 2012).

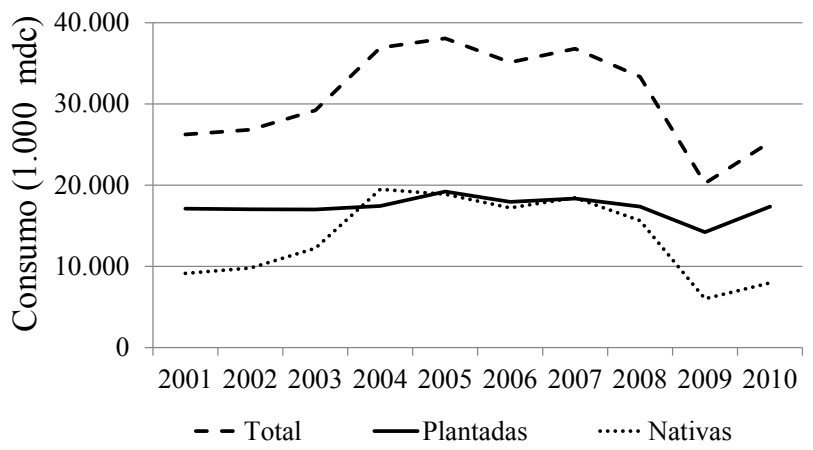

Figura 4. Consumo brasileiro de carvão vegetal, conforme a origem da matéria-prima (Fonte: Rezende \& Santos, 2012).

Apesar de ser um excelente combustível e da larga aplicação, o carvão vegetal possui algumas características e propriedades desfavoráveis que restringem sua utilização, tais como a baixa densidade, friabilidade e a desuniformidade granulométrica, que restringem sua utilização (Antunes, 1982; Fontes et al., 1989).

Dessa forma, o desenvolvimento do mercado de péletes de resíduos de madeira está permitindo aumentar as exportações dessa biomassa, especialmente para países da Europa, o que deve ampliar sua importância na matriz energética dos países desenvolvidos. Porém, mesmo hoje, a biomassa de madeira tem um papel de destaque na oferta global de energia. Segundo a
International Energy Agency (IEA), a biomassa de madeira responde por cerca de $8,7 \%$ da matriz energética mundial (Vidal \& Hora, 2011).

Os péletes de madeira de eucalipto são considerados como combustível sólido de resíduos de madeira prensada. A peletização diminui a umidade da madeira e aumenta sua densidade, ampliando as possibilidades de comércio internacional, sendo hoje a biomassa sólida para fins energéticos mais negociada no mundo. Sua alta densidade permite um armazenamento compacto e um transporte mais econômico a longas distâncias, além de ser um combustível limpo e eficiente, permitindo combustão sem muita produção de fumaça e liberando menos dióxido de carbono do que qualquer outro combustível fóssil, e ainda com menor liberação de monóxido de carbono que outros combustíveis (Vidal \& Hora, 2011).

Em 2012 já havia 20 plantas industriais de péletes em funcionamento no Brasil, além de novos projetos anunciados, estando a maioria localizada na Região Sul. Entre os fatores que levam à consolidação do mercado de péletes no cenário nacional, destacam-se a redução da dependência dos combustíveis fósseis, a disponibilidade de resíduos gerados pelo setor madeireiro e a crescente demanda estimulada por mecanismos governamentais de incentivo. A produção, o consumo, a exportação e a importação brasileira de péletes ainda são ínfimas, mas a tendência é que, em longo e médio prazos, a demanda cresça, estimulando a produção, o consumo interno e as exportações (Anuário..., 2012a).

\section{Madeira de eucalipto como fonte de celulose e papel}

A celulose e o papel de eucalipto constam entre os principais produtos de exportação do Brasil, ocupando uma posição de destaque na balança comercial do país. Em 2012 esse setor foi responsável por 16,7\% do saldo da balança comercial, contribuindo com US\$ 1,9 bilhões do total do superávit (US\$ 11,3 bilhões) (Valverde et al., 2012). Em 2010 foram exportados US\$ 6,8 bilhões por esse setor que utiliza $100 \%$ de madeira de florestas plantadas, sendo mais de $85 \%$ de eucalipto (Associação Brasileira de Celulose e Papel, 2012) e, ainda, em 2011 o Brasil foi responsável por 21\% do mercado internacional de celulose (Anuário..., 2012a). Por causa desta importante atividade agro-industrial e do apoio de instituições governamentais de pesquisa e universidades, o Brasil ocupa posição de liderança mundial em silvicultura e melhoramento de eucalipto (Figura 5). 


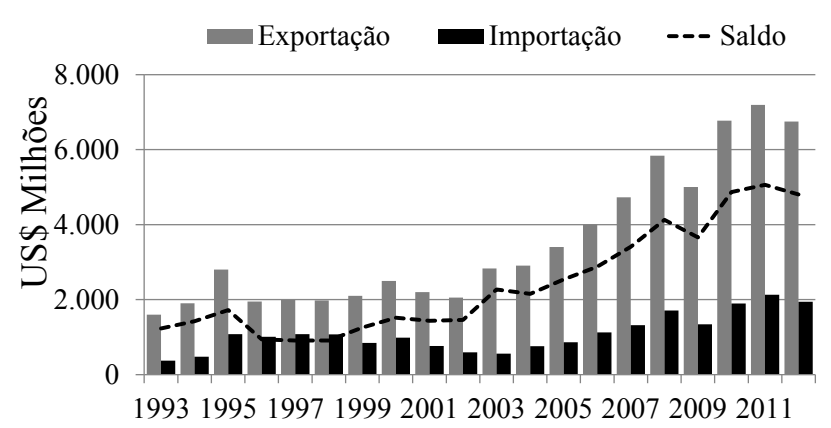

Figura 5. Evolução da balança comercial do setor de celulose e papel 1993-2012 (Fonte: Anuário..., 2012b).

O eucalipto produzido no Brasil se destina basicamente à produção de celulose e papel e ao carvão vegetal que abastece as siderúrgicas (Oliveira et al., 2000). As indústrias brasileiras que usam o eucalipto como matériaprima para a produção de papel, celulose e demais derivados representam $4 \%$ do PIB, $8 \%$ das exportações e geram aproximadamente 150 mil empregos (Chaul \& Tibiriça, 2006).

O Brasil tem a maior área plantada de eucalipto do mundo, com 4,9 milhões de hectares, e é o maior produtor mundial da celulose branqueada dessa essência, com cerca de 11,3 milhões de toneladas por ano (Anuário..., 2012b) com produção crescente, como pode ser observado na Figura 6. O país detém ainda o maior índice médio de produtividade em florestas plantadas de eucalipto (44 $\left.\mathrm{m}^{3} \mathrm{ha}^{-1} \mathrm{ano}^{-1}\right)$ (Valverde et al., 2012), tendo sido em 2011 o quarto maior produtor mundial de celulose, ficando atrás apenas dos EUA, China e Canadá, e o nono maior produtor de papel (Anuário..., 2012b).

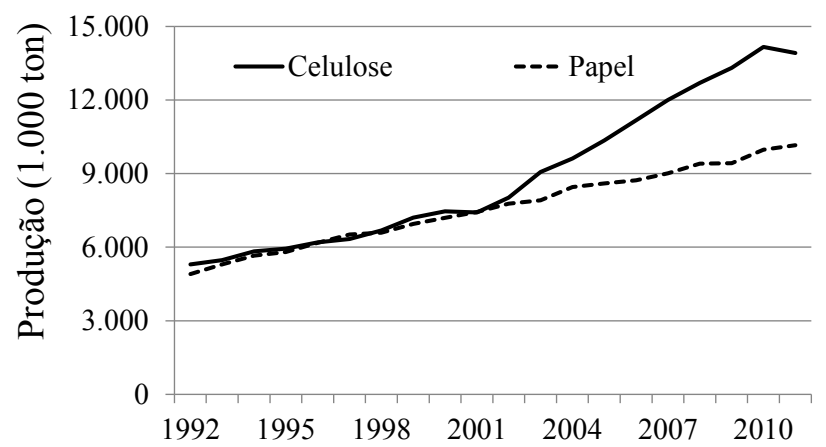

Figura 6. Evolução da produção brasileira de celulose e papel (Fonte: Anuário..., 2012b).
Nos últimos anos, mesmo após a decisão do governo brasileiro de restringir a compra de terras por empresas que possuam composição majoritária de capital estrangeiro e a crise mundial, que reduziu a atividade econômica nos países da União Europeia e nos Estados Unidos (países importadores de produtos florestais ou da cadeia de base florestal), foi verificado um crescimento de $2,5 \%$ da área de florestas de eucalipto (120 mil hectares) (Anuário..., 2012a).

De modo geral, os processos de polpação para produção de celulose podem ser divididos em mecânicos (pastas de alto rendimento), quimiomecânicos e químicos (Xu \& Zhou, 2007). O Brasil é um grande produtor de polpa química, com uma produção de 13,4 milhões de toneladas, ao passo que o setor de polpa mecânica é responsável pela produção de apenas 435 mil toneladas, por causa da menor diversidade de aplicação para essas polpas (Anuário..., 2012b).

Apesar da menor produção, o setor de polpa mecânica é de grande importância para algumas aplicações, como papel cartão e jornal, e são caracterizadas pelo elevado aproveitamento da matéria-prima (80-95\% de rendimento) e por manterem praticamente todos os compostos encontrados na madeira sem grandes alterações na composição química. As polpas químicas são utilizadas para produção dos mais diversos tipos de papel, como embalagens, papéis sanitários e de impressão/escrita.

Destaque especial pode ser dado a um segmento do setor de polpa química não destinada à produção de papel, denominado polpa química para dissolução, e que se encontra em ascensão no mercado, pela possibilidade de criação de vários produtos em substituição aos derivados do petróleo ou outros produtos que sejam agressivos ao meio ambiente. No setor têxtil, a polpa química para dissolução concorre com as fibras do algodão, sendo a oferta e o preço dessas fibras um sinalizador para a maior ou menor demanda pelas fibras de madeira.

Além dos produtos diretos da celulose, o setor de celulose e papel também passa por uma mudança conceitual, em que a celulose e o papel deixam de ser as únicas metas de produção e passam a ser pensados como produtos principais, enquanto outros produtos (derivados das hemiceluloses e lignina recuperadas durante o processo, como os lignosulfonatos) são cada 
vez mais atrativos por causa do maior aproveitamento da matéria-prima e, ao mesmo tempo, possibilitam agregar maior valor aos produtos (Colodette, 2012).

\section{Madeira de eucalipto como fonte de bioprodutos}

A utilização da madeira de eucalipto como fonte de bioprodutos é justificada principalmente pelo uso da madeira dessa essência pelas indústrias de celulose. A transformação das indústrias de celulose em grandes biorrefinarias possibilita não somente a produção de polpa e papel, mas uma variedade de produtos (Ferraz, 2007; Martin, 2011; Martins, 2012).

As vantagens na utilização das plantas de celulose na produção de bioprodutos são: i) a experiência nas operações de produção, colheita, transporte e armazenamento de grandes volumes de madeira/ biomassa; ii) infraestrutura já instalada para o processamento químico da madeira segundo normas nacionais e internacionais; iii) localização normalmente em áreas rurais, o que possibilita a sinergia entre madeira e resíduos da agricultura, como de gramíneas (Colodette, 2012).

A utilização dos resíduos de madeira e não-madeira obtidos durante o processamento das toras, desde a colheita até a indústria onde serão processadas, é uma alternativa para aplicação do conceito de biorrefinaria. A árvore depois de abatida tem seu fuste enviado para a indústria de processamento. Entretanto, as demais partes podem ser reaproveitadas. Segundo os dados de um inventário de madeira de eucalipto de 8 anos, são gerados aproximadamente $12 \%$ de casca e $17 \%$ de resíduos arbóreos, como galhos e folhas (Couto \& Brito, 1980). Esse material quando manipulado corretamente pode ser fonte de muitos produtos de elevado valor agregado, como óleos vegetais.

Os produtos de uma biorrefinaria podem ser agrupados em: i) biocombustíveis sólidos ("coque", lignina e bagaço), líquidos (etanol, metanol e óleo combustível) e gasosos (gás de síntese, metano e hidrogênio); ii) bioquímicos (carvão ativado, aditivos de combustíveis, fenóis, furfural, óleos, ácido acético, surfactantes e agroquímicos); iii) biomateriais (óleos, pigmentos, tintas, vernizes, detergentes, desinfetantes, adesivos, biopolímeros e filmes) (Colodette, 2012; Martins, 2012).

Dentre os componentes da madeira mais visados para a prática da biorrefinaria destacam-se a lignina e as hemiceluloses. A lignina é um componente da madeira indesejável na produção de celulose e papel e está presente em alta concentração no licor negro.
Por isso, se mostra altamente atrativa para produção de bioprodutos. Pode ser obtida por diferentes processos químicos de cozimento, como sulfito, kraft, organosolv e enzimático (Santos \& Colodette, 2013).

De acordo com o processo de obtenção, a lignina pode ter diferentes aplicações: i) a lignina isolada do processo sulfito (ligninossulfonatos) pode ser usada como ligante (aglutinante em alimentos para animais e ligante em asfalto), ii) a lignina kraft isolada pelo processo Lignoboost pode ser comercializada como energia na forma de combustível em pó, bem como na fabricação de fibras de carbono (Kadla et al., 2002), iii) a lignina organosolv vem sendo estudada para produção de fibras de carbono desde 1993 (Uraki et al., 1993). Outras aplicações conferidas à lignina são a produção de espumas de poliuretanas, resinas fenólicas e epóxi, fonte de fenol e etileno (Lora \& Glasser, 2002), vanilina, fibras de carbono em geral, carvão ativado e corretivos para solo (Santos \& Colodette, 2013).

A seguir serão destacadas as mais recentes pesquisas desenvolvidas pelos países que são referência em biorrefinaria. Na Suécia, por exemplo, a obtenção de energia e produção de diversos materiais e produtos químicos de lignina, celulose, cascas e outros resíduos florestais, conta com um projeto destinado à produção de dimetil éter por meio de gaseificação de licor negro. $\mathrm{Na}$ Noruega, estuda-se a viabilidade de produzir biodiesel de madeira com a previsão de construção de uma usina no sudeste do país. A Dinamarca possui uma planta de demonstração de tecnologias básicas, atuando na produção de bioetanol celulósico de uma ampla gama de biomassa, tais como cavacos de madeira, resíduos de jardim, cevada e trigo. A Islândia também possui instalada uma planta de demonstração de biorrefinaria de matéria-prima vegetal, utilizando processos como hidrólise ácida e fermentação de açúcares, em que o principal produto estudado é o bioetanol. No Canadá, considerado um dos países que mais visualiza oportunidades de biorrefinaria para a indústria de celulose e papel, existem três principais temas de investigação: matérias-primas, conversão e tecnologias de separação, e mercados para os produtos. Finalmente, a Finlândia possui três consórcios para estabelecer biorrefinarias de segunda geração no país, com foco na gaseificação de biomassa e síntese por Fischer-Tropsch (Martin, 2011).

Muitos desses produtos podem ser conseguidos pela utilização da madeira de eucalipto, utilizando rotas 
paralelas ao processo de produção de celulose, seja utilizando os resíduos da madeira ou do processo (licores de estágios de extração e licor negro, por exemplo). Entretanto, os maiores desafios para que esses produtos seja economicamente viáveis são as tecnologias de conversão da biomassa como pré-processamento e prétratamentos (Korpinen \& Fardin, 2008; Colodette, 2012).

No Brasil existe um consórcio internacional entre empresas brasileiras, União Europeia e universidade (Universidade Federal de Viçosa) denominado Lignodeco (Lignocellulose Deconstruction) que objetiva estudar pré-tratamentos enzimáticos, químicos e mecânicos para a desconstrução da parede celular de madeiras brasileiras de rápido crescimento (eucalipto) e de materiais não lenhosos (capim elefante) para produção de biocombustíveis, polpas especiais e produtos químicos (aditivos de polpa celulósica). Os pré-tratamentos visam separar os constituintes da madeira para que possam ser estudadas as alterações químicas sofridas por esses constituintes, bem como identificar as possibilidades de utilização desses componentes após sua separação.

\section{Considerações finais}

As espécies florestais do gênero Eucalyptus são as mais importantes para a indústria de base florestal, por serem utilizadas pelos principais segmentos industriais, inclusive em substituição a outras espécies florestais como pinus.

O setor de celulose e papel busca cada vez mais utilizar os componentes das madeiras de eucalipto na sua totalidade para geração de novos produtos de maior valor agregado, dentro do conceito de biorrefinarias.

Muitos obstáculos, como o elevado custo de transformação e tecnologias mais baratas para produção de bioprodutos, ainda precisam ser vencidos para que produtos importantes, tais como os combustíveis possam ser produzidos economicamente de forma viável utilizando-se madeira e seus resíduos.

\section{Referências}

ANTUNES, R. C. Briquetagem de carvão vegetal. In: PENEDO, W. R. Produção e utilização do carvão vegetal. Belo Horizonte: CETEC, 1982. p. 197-206.

ASSIS, A. L. Avaliação de modelos polinomiais segmentados e não segmentados na estimativa de diâmetros e volumes comerciais de Pinus taeda. 2000. 198 f. Dissertação (Mestrado em Engenharia Florestal) - Universidade Federal de Lavras, Lavras, MG.
ANUÁRIO ESTATÍSTICO DA ABRAF 2012: ano base 2011. Brasília, DF: ABRAF, 2012a. Disponível em: <www.abraflor.org. br/estatisticas.asp>. Acesso em: 10 abr. 2013.

ANUÁRIO ESTATÍSTICO 2011/2012. São Paulo: BRACELPA, 2012b. Disponível em: <www.bracelpa.org.br>. Acesso em: 10 abr. 2013

ASSOCIAÇÃO BRASILEIRA DE CELULOSE E PAPEL. Panorama do Setor. 2012. Disponível em: <www.bracelpa.org.br > Acesso em: 15 abr. 2013.

ASSOCIAÇÃO BRASILEIRA DE FLORESTAS RENOVAVEIS. Relatório estatístico. Belo Horizonte, ABRACAVE, 1995. 12 p.

BOSCARDIN, P. M. D. Morfoanatomia, fitoquímica e atividades biológicas de Eucalyptus benthamii maiden et Cambage - Myrtaceae. 2009. 139 f. Dissertação (Mestrado em Ciências Farmacêuticas) - Universidade Federal do Paraná, Curitiba.

BRITO J.O. O uso energético da madeira. Estudos Avançados, Piracicaba, v. 21, n. 59, p. 185-193, 2007.

BRITO, J. O. Usos energéticos do Eucalyptus grandis. In: JORNADAS FLORESTALES DE ENTRE RIOS, 9., 1994, Concordia. Proceedings... Serviço Florestal: 1994. 14 p.

CHAUL, T. N.; TIBIRIÇA, L. G. Viabilidade econômica de florestas de eucalipto no Estado de Goiás. 2006. Disponível em: <www. ucg.br/ucg/prope/cpgss/Arquivos>. Acesso em: 05 abr. 2013.

COLODETTE, J. L. Biorrefinaria da madeira: o novo foco da pesquisa em celulose e papel. In: SIMPÓSIO DE PÓS-GRADUAÇÃO EM CIÊNCIAS FLORESTAIS, 7., 2012, Viçosa, MG. Anais... Viçosa, MG: Laboratório de Celulose e Papel, 2012.

COUTO, H. T. Z.; BRITO, J. O. Inventário de resíduos florestais. Série Técnica IPEF, Piracicaba, v. 1, n. 2, p. A1-A13, 1980.

FERRAZ, A. Biopulping developments in Brazil. O Papel, São Paulo, v. 68, n. 7, p. 44-53, 2007.

FERREIRA, M.; SANTOS, P. E. T. Melhoramento genético florestal dos Eucalyptus no Brasil: breve histórico e perspectivas. In: IUFRO CONFERENCE ON SILVICULTURE AND IMPROVEMENT OF EUCALYPTS, 1997, Salvador. Anais... Colombo: Embrapa-CNPF, 1997. p. 14-34.

FERREIRA, O. P. Madeira: uso sustentável na construção civil. São Paulo: IPT, 2003. 59 p.

FONTES, P. J. P.; QUIRINO, W. F.; OKINO, E. Y. A. Aspectos técnicos de briquetagem de carvão vegetal no Brasil. Brasília, DF: LPF, 1989. 14 p.

FAO. 2011 Global forest products facts and figures. 2012. Disponível em: <www.fao.org/forestry/statistics>. Acesso em: 15 jun. 2013.

FAO. Forest products Yearbook. 2011. Disponível em: <www.fao. org/forestry/statistics>. Acesso em: 10 abr. 2013.

FAO. Wood energy: promoting sustainable energy systems. 2003. Disponível em: <www.foris.fao.org/static/>. Acesso em: 14 abr 2013.

GARCIA, C. H.; PIMENTEL-GOMES, F. Forest outlines of Brazil. Revista de Agricultura, Piracicaba, v. 67, p. 105-117, 1992.

GESUALDO, F. A. R. Estruturas de madeira. Uberlândia, UFU, 2003. 105 p. Apostila. 
GIT FORESTRY CONSULTING. Global Eucalyptus Map 2009. Disponível em: <www.git-forestry.com/downloads/GIT_Forestry_Global_Eucalyptus_Map_2009_Marketing_Campaign_ENG. pdf $>$. Acesso em: 1 nov. 2013.

KADLA, J. F.; KUBO, S.; VENDITTI, R. A.; GILBERT, R. D.; COMPERE, A. L. GRIFFITH, W. Lignin-based carbon fibers for composite fiber applications. Carbon, v. 40, n. 15, p. 2913-2920, 2002 .

KORPINEN, R.; FARDIM, P. Wood chip screenings as a source of energy, Kraft pulp and functional chemicals: a Nordic perspective. O Papel, São Paulo, v. 69, n. 5, p. 56-63, 2008.

LIMA, W. P. Impacto ambiental do Eucalipto. São Paulo: Ed USP, 1993. 302 p.

LORA, J. H.; GLASSER, W. G. J. Recent industrial applications of lignin: a sustainable alternative to non-renewable materials. Polymers Environment, v. 10, p. 39-48, 2002.

MADEIRAMBIENTE Madeira: excelente para grandes estruturas. 2013. Disponível em: <www.madeirambiente.com.br/madeira-grandes-estruturas>. Acesso em: xx abril 2013.

MAIA, S. F. D; GOMES, M. L. B., SILVA, R. M. A substituição da madeira por peças fabricadas de plásticos reciclados na construção civil de casas populares: um apelo a sustentabilidade. In: ENCONTRO NACIONAL DE ENGENHARIA DE PRODUÇÃO, 31., 2011, Belo Horizonte. Anais... ABEPRO, 2011. 13 p.

MARTIN, C. Biorrefinaria industrial. O Papel, São Paulo, n. 3, p. 26-32, 2011.

MARTIN, C. Celulose de fibra curta conquista novos mercados. O Papel, São Paulo, n. 2, p. 34-36, 2012.

MARTINS, A. F. Biorrefinarias. In: INSTITUTO NACIONAL DE EFICIÊNCIA ENERGÉTICA. Biomassa e Energia. Santa Maria: INEE, 2012. Disponível em: <www.inee.org.br/down_loads/biomassa/Apres\%20INEE.pdf>. Acesso em: 8 abr. 2013.

MURARA JUNIOR, M. I.; ROCHA, M. P.; TIMOFEICZYK JUNIOR, R. Rendimento em madeira serrada de pinus taeda para duas metodologias de desdobro. Floresta, Curitiba, v. 35, n. 3, p. 473-483, 2005.
OLIVEIRA, A. D.; SCOLFORO, J. R. S.; SILVEIRA, V. P. Análise econômica de um sistema agro-silvo-pastorial com eucalipto implantado em região de cerrado. Ciência Florestal, Santa Maria, RS, v. 10, n. 1, p. 1-19, 2000.

PORTAL DAS ENERGIAS RENOVÁVEIS. Conversão: biomassa sólida. 2011. Disponível em: <www.energiasrenovaveis.com/DetalheConceitos.asp?ID_conteudo-=2\&ID_area $=2 \& I D \_s u b \_a r e a=2>$. Acesso em: 4 abr. 2013.

REZENDE, J. B.; SANTOS, A. C. Cadeia produtiva do carvão vegetal. In: REZENDE, J. B. Cadeias produtivas do complexo agroindustrial de florestas plantadas em Minas Gerais: estrutura e dinâmica. Viçosa, MG: EPAMIG, 2012. p. 23-70.

SANTOS, V. L. S.; COLODETTE, J. L. Produção de lignina da madeira. In: SANTOS, F.A.; COLODETTE, J. L.; QUEIROZ, J. H. Bionergia e biorefinaria. Viçosa, MG: Ed da UFV, 2013. p. 509-527.

SOARES, T. S.; VALE, A. B.; LEITE, H. G.; MACHADO, C. C. Árvore, Viçosa, MG, v. 27, n. 6, p. 811-820, 2003.

URAKI, Y.; KUBO, S.; SANO, Y.; SASAYA, T.; OGAWA, M. Melt spinning of organosolv lignin. In: INTERNATIONAL SYMPOSIUM ON WOOD AND PULPING CHEMISRY, 7.,1993, Japão. Proceedings... Tappi, 1993. 4 p.

VALVERDE, A. E. L.; VALVERDE, S. R.; ALVARENGA, A. P.; MARQUES, G. M.; MENDONÇA, F. M.; OLIVEIRA, P. R. S. Cadeia produtiva de celulose. In: REZENDE, J. B. Cadeias produtivas do complexo agroindustrial de florestas plantadas em Minas Gerais: estrutura e dinâmica. Viçosa, MG: EPAMIG, 2012. p. 71-92.

VIDAL, A. C. F; HORA, A. B. Perspectivas do setor de biomassa de madeira para geração de energia. BNDES Setorial, Rio de Janeiro, v. 33, p. 261-314, 2011.

WORLD RESOURSES INSTITUTE. Earth Trends: The Environmental Portal. Disponível em: <www.earthtrends.wri.org > Acesso em: 4 abr. 2013.

XU, E. C.; ZHOU, Y. Synergistic effects between chemical mechanical pulps and chemical pulps form hardwoods Tappi Journal, Atlanta, v. 6, n. 11, p. 4-9, 2007. 